https://helda.helsinki.fi

\title{
Gödel on many-valued logic
}

\section{Lethen, Tim}

2021-02-22

Lethen , T 2021 , ' Gödel on many-valued logic ' , The Review of Symbolic Logic , pp. 1-18 . https://doi.org/10.1017/s

http://hdl.handle.net/10138/336145

https://doi.org/10.1017/s1755020321000034

submittedVersion

Downloaded from Helda, University of Helsinki institutional repository.

This is an electronic reprint of the original article.

This reprint may differ from the original in pagination and typographic detail.

Please cite the original version. 
GÖDEL ON MANY-VALUED LOGIC

TIM LETHEN

\begin{abstract}
This paper collects and presents unpublished notes of Kurt Gödel concerning the field of many-valued logic. In order to get a picture as complete as possible, both formal and philosophical notes, transcribed from the Gabelsberger shorthand system, are included.
\end{abstract}

Keywords: many-valued logic, Kurt Gödel

Mathematics Subject Classification (MSC2020): 03-03, 03A05, 03B50

§1. Introduction. As Jan von Plato outlines in his book 'The Great Formal Machinery works - Theories of Deduction and Computation at the Origins of the Digital Age' (von Plato 2017, p. 2), 'our present information society owes part of its existence to a well hidden but essential line of development, the theoretical study of logic and foundations of mathematics,' and he hastens to add 'boosted by Gödel's discovery,' refering to Gödel's incompleteness theorem and the therewith closely associated specification of the notion of algorithmic computability. But whereas Gödel's path to incompleteness has recently been studied in great detail (cf. von Plato 2020), his contributions to the field of many-valued logic are certainly less know or at least, say, less famous. Here again, many applications can be found in the areas of computer science and artificial intelligence, but the roots of these modern applications certainly have to be sought again in philosophy and foundational studies.

To obtain a picture as complete as possible of Gödel's role in this complex process, this paper will mainly study his unpublished sources concerning manyvalued logic, trying to merge both his formal work and his philosophical considerations. For this purpose, the relevant material has been transcribed from the Gabelsberger shorthand system, which was used by Gödel for all his personal and scientific notes. English translations are given throughout.

The following section will first give an overview of the historical development of many-valued logics starting with Jan Lukasiewicz's and Emil Post's initiating publications in and around 1920. We concentrate on the various definitions of the logical operations, implication and negation as well as disjunction and conjunction. This approach will enable us to place Gödel's only publication on many-valued logic (Gödel 1932) and its relation to intuitionitic logic in a surrounding historical context, clearly pointing out where his ingenious construction

Received by the editors December 6, 2020. 
originated. At the same time, it will also enable us to shed light upon unpublished work found in one of his Arbeitshefte where he investigates a new kind of disjunction and conjunction, nowadays often attributed to Łukasiewicz, and their relation to other well-established connectives. These original investigations are outlined in Section 3. Section 4 will then present material found in Gödel's philosophical notebook MaxPhil III which was written in parallel at exactly the same time. These notes demonstrate in an exemplary way the omnipresent and close interconnection between Gödel's formal work on the one side and his philosophical considerations on the other. Section 5 then presents brief philosophical notes on first-order many-valued logic, which can be taken to lead to a new kind of a continuously differentiable implication. Finally, Section 6 considers an early metaphysical application of higher-order many-valued logic, which is closely related to Gödel's ontological proof for the existence of God.

Two sources on many-valued logic will be mentioned here only very briefly, as they are currently being prepared for publication. The first one is part of a chapter from a manuscript preparing a book on logic and foundations, which Gödel had agreed in 1931 to write in collaboration with Arend Heyting. Gödel never finished his envisaged part and finally Heyting's work was published separately under the title 'Mathematische Grundlagenforschung: Intuitionismus, Beweistheorie' (Heyting 1934). The chapter contains remarks on Łukasiewicz's and Post logics as well as on results presented in Eukasiewicz \& 3 Tarski (1930). It also mentions Paul Bernays' independence proofs based on many-valued systems published in Bernays (1926), which can be regarded as a basis for Gödel's own many-valued logics published in Gödel (1932), see below. The second source not further explored here is a short excerpt from Post (1921) which can be found in Gödel's Altes Excerptenheft, ${ }^{1}$ written in or shortly after 1931 while preparing the manuscript for the just mentioned book.

§2. The early history of many-valued logical connectives. In this section, we briefly sketch the history of many-valued logic between 1920 and 1940. Although many other detailed accounts of this history have been compiled, ${ }^{2}$ it seems to be important here to describe the background against which Gödel developed and investigated new operators he introduced in his Arbeitsheft in 1940. Therefore, we mainly concentrate on those works which introduce logical connectives in a definite way. In order to facilitate comparison between the given definitions, we denote a third truth-value as $\frac{1}{2}$ throughout, which is also Gödel's notation in 1940. Generalising this notation, finite sets of more than two truthvalues are given as $\left\{0, \frac{1}{m-1}, \frac{2}{m-1}, \ldots, 1\right\}, 1$ always being the only designated 'true' value.

In June 1920, Jan Lukasiewicz delivered a talk before the 207th meeting of the Polish Philosophical Society in Lwów entitled 'On three-valued logic'

\footnotetext{
${ }^{1}$ Kurt Gödel Papers, Box 6a, Folder 58, item accession 030079, on deposit with the Manuscripts Division, Department of Rare Books and Special Collections, Princeton University Library. Used with permission of Institute for Advanced Study. Unpublished Copyright Institute for Advanced Study. All rights reserved.

${ }^{2}$ See, for example, Gottwald (2001, chapter 4).
} 
(Eukasiewicz 1920). In this talk, Łukasiewicz introduces a third logical value representing 'possibility,' stating that the system he accepts 'in the present state of his research' is the one "which deviates the least from the "two-valued" logic.' The system is based on the operation of implication as its only primitive. Negation, disjunction, and conjunction are then derived as $\sim a \stackrel{\text { Def }}{=} a \supset 0$, $a \vee b \stackrel{\text { Def }}{=}(a \supset b) \supset b$, and $a \wedge b \stackrel{\text { Def }}{=} \sim(\sim a \vee \sim b)$, respectively, thus yielding the following tables. ${ }^{3}$

\begin{tabular}{|c|c|c|c|c|c|c|c|c|c|c|c|}
\hline$\supset$ & 0 & $\frac{1}{2}$ & & $\sim$ & $\wedge$ & 0 & & 1 & $\vee$ & 0 & \\
\hline 0 & 1 & 7 & 0 & 1 & 0 & 0 & ) & 0 & 0 & 0 & \\
\hline$\frac{1}{2}$ & $\frac{1}{2}$ & 1 & $\frac{1}{2}$ & $\frac{1}{2}$ & $\frac{1}{2}$ & 0 & & $\frac{1}{2}$ & $\frac{1}{2}$ & $\frac{1}{2}$ & \\
\hline & 0 & $\frac{1}{2}$ & 1 & 0 & 1 & 0 & & 1 & 1 & 1 & \\
\hline
\end{tabular}

Note that the equations $a \vee b=\max \{a, b\}$ and $a \wedge b=\min \{a, b\}$ hold. Further information about the philosphical background against which Łukasiewicz developed his idea of a three-valued logic can be found in Eukasiewicz (1930) and Malinowski (1993, chapter 2).

Independently of the Lwów-Warsaw school, in 1920, Emil L. Post developed a series of many-valued logics which contained an arbitrarily large, albeit finite number of truth values. In Post (1921), he writes:

One class of such [generalised] systems, and we study these in detail, seems to have the same relation to ordinary logic that geometry in a space of an arbitrary number of dimensions has to the geometry of Euclid. Whether these 'non-Aristotelian' logics and the general development which includes them will have a direct application we do not know;

Post's systems consist of a set of $m$ ordered truth-values $\left\{0, \frac{1}{m-1}, \frac{2}{m-1}, \ldots, 1\right\}$ and two primitive operations, a 'generalised' negation which permutes the truthvalues, and a disjunction, defined as follows:

$$
\begin{aligned}
\sim a \stackrel{\text { Def }}{=} \begin{cases}0 & \text { for } a=1 \\
\frac{i+1}{m-1} & \text { for } a \neq 1, a=\frac{i}{m-1}\end{cases} \\
\\
a \vee b \stackrel{\text { Def }}{=} \max \{a, b\}
\end{aligned}
$$

In order to define a conjunction, Post then introduces a second kind of negation, which may well be regarded as a generalisation of Łukasiewicz's three-valued negation, and then proceeds with a variant of De Morgan's Law:

$$
\begin{gathered}
\approx a \stackrel{\text { Def }}{=} 1-a \\
a \wedge b \stackrel{\text { Def }}{=} \approx(\approx a \vee \approx b)
\end{gathered}
$$

Again, the equation $a \wedge b=\min \{a, b\}$ holds.

In 1922, Lukasiewicz developed the idea of an infinite many-valued logic, which was finally published in Eukasiewicz (1930). Here, he writes:

\footnotetext{
${ }^{3}$ Throughout this paper, the first argument of an operation is always given in the leftmost column.
} 
It was clear to me from the outset, that among all the many-valued systems only two can claim any philosphical significance: the threevalued and the infinite-valued ones. For if values other than ' 0 ' and ' 1 ' are interpreted as 'the possible', only two cases can reasonably be distinguished: either one assumes that there are no variations in degree of the possible and consequently arrives at the three-valued system; or one assumes the opposite, in which case it would be most natural to suppose (as in the theory of probabilities) that there are inifinitely many degrees of possibility, which leads to the infinite-valued propositional calculus.

He then goes on to define the two primitive operations, implication and negation, for any $a, b \in[0,1]$ :

$$
\begin{gathered}
a \supset b \stackrel{\text { Def }}{=} \begin{cases}1 & \text { for } a \leq b \\
1-a+b & \text { for } a>b\end{cases} \\
\sim a \stackrel{\text { Def }}{=} 1-a
\end{gathered}
$$

Finally, disjunction and conjunction are derived as follows:

$$
\begin{gathered}
a \vee b \stackrel{\text { Def }}{=}(a \supset b) \supset b \\
a \wedge b \stackrel{\text { Def }}{=} \sim(\sim a \vee \sim b)
\end{gathered}
$$

Again, it can be verified that $a \vee b=\max \{a, b\}$ and $a \wedge b=\min \{a, b\}$ hold. Note that Post's system can easily be extended to Łukasiewicz's system if the negation (3) denoted as $\approx$ is used.

Gödel's only published contribution to the subject of many-valued logic appeared in 1932, when he proved that intuitionistic propositional logic cannot be regarded as a finite system of many-valued logic (Gödel 1932). In this short paper he proposes finite sets of truth-values $\left\{0, \frac{1}{m-1}, \frac{2}{m-1}, \ldots, 1\right\}$, on which he defines the following operations:

$$
\begin{gathered}
a \supset b \stackrel{\text { Def }}{=} \begin{cases}1 & \text { for } a \leq b \\
b & \text { for } a>b\end{cases} \\
\sim a \stackrel{\text { Def }}{=} \begin{cases}0 & \text { for } a \neq 0 \\
1 & \text { for } a=0\end{cases} \\
a \vee b \stackrel{\text { Def }}{=} \max \{a, b\} \\
a \wedge b \stackrel{\text { Def }}{=} \min \{a, b\}
\end{gathered}
$$

Again, the system can easily be extended to an infinity of truth-values. Note that implication and negation differ from both Łukasiewicz's and Post's definitions.

In his paper, Gödel does not give any indication as to where the idea of his construction originated. It has to be noted though that the three-valued version of his system appeared already two years earlier in the appendix of Arend Heyting's paper 'Die formalen Regeln der intuitionistischen Logik' (Heyting 1930), which Gödel had studied very carefully. In this appendix, Heyting proves the 
independence of the eleven axioms he introduces for his system $H$ of intuitionistic logic. For this purpose, eleven different many-valued logics are constructed, each one validating all but one of the axioms. ${ }^{4}$ Finally, in 'Gruppe XII,' a three-valued logic is presented which validates all the eleven axioms but not the formula $\sim \sim a \supset a$, thus showing that the axioms do not yield a system of classical propositional logic. It is this very logic in group XII which Gödel generalised for his purpose to an arbitrary (finite) number of truth-values. ${ }^{5}$ It is given in Heyting's paper as follows:

\begin{tabular}{|c|c|c|c|c|c|c|c|c|c|c|c|}
\hline & 0 & $\frac{1}{2}$ & 1 & & $\sim$ & $\wedge$ & 0 & $\frac{1}{2}$ & 1 & $V$ & 0 \\
\hline 0 & 1 & 1 & 1 & 0 & 1 & 0 & 0 & $\overline{0}$ & 0 & 0 & 0 \\
\hline & 0 & 1 & 1 & $\frac{1}{2}$ & 0 & $\frac{1}{2}$ & 0 & $\overline{\mathbf{2}}$ & $\frac{1}{2}$ & $\frac{1}{2}$ & $\frac{1}{2}$ \\
\hline & 0 & $\frac{1}{2}$ & 1 & 1 & 0 & 1 & 0 & $\frac{1}{2}$ & 1 & 1 & 1 \\
\hline
\end{tabular}

It should be added that Heyting in turn attributes his proof method to Paul Bernays who already used it in his habilitation thesis (Bernays 1918) as early as 1918, parts of which were finally published in 1926 as 'Axiomatische Untersuchung des Aussagen-Kalküls der "Principia Mathematica"' (Bernays 1926). Details about the origins of Bernays' method can be found in Zach $(1999, \S 4)$, where the following remark is given:

It may be debated whether Bernays's systems can properly be called many-valued logics, but they certainly had the distinction of being useful in proving independence results in logic, an achievement considered important.

About ten years later, at the end of 1941, Gödel, in one of his notebooks called Resultate Grundlagen (Results on Foundations), ${ }^{6}$ gives another proof that intuitionistic propositional logic is not many-valued. The proof is based on topological methods and translations between Heyting's calculus and Lewis' modal calculus. The theorem in question is given under the heading 'Existenz von unendlich vielen Wahrheitswerten im Heyting und Lewiskalkül' (Existenz of infinitely many truth-values in Heyting and Lewis calculus) as follows, $\mathfrak{B}$ denoting the provability operator. Details will be given in Gödel (2021).

I. Es gibt unendlich viele Formeln des Lewis-Kalküls (und zwar solche, die mit $\mathfrak{B}$ beginnen und vor jeder Variablen $\mathfrak{B}$ ) mit einer Variablen, die paarweise nicht äquivalent sind.

\footnotetext{
${ }^{4}$ Of these logics, four are two-valued, three are three-valued, one is four-valued, and three have an infinite number of truth-values.

${ }^{5}$ Papers prepared for Hans Hahn's logic seminar in 1931/1932 clearly testify to the generalisation of Heyting's three-valued logic. Here, Gödel very briefly notes (Kurt Gödel Papers, Box 7b, Folder 15, item accession 040029):

'Heyting Ansatz 3-wertige,

3. Wahrheitswert $=$ wenn man die Falschheit widerlegt, aber die Wahrheit nicht beweisen kann,

Unmöglichkeitsbew. $p \equiv q \vee p \equiv r \vee q \equiv r$,

allgem. $\sum_{1 \leqq i \leqq n+1} p_{i} \equiv p_{k}$ für $n$-wertige Logik.'

${ }^{6}$ Resultate Grundlagen (Kurt Gödel Papers, Box 6c, Folders 82-86, item accession 030115119.) is a collection of four notebooks in which Gödel presents personal results on logic and foundations. They are going to be published as Gödel (2021).
} 
II. Es gibt unendlich viele paarweise nicht äquivalente Formeln des Heyting-Kalküls mit einer Variablen.

[ I. There is an infinite number of formulas of the Lewis calculus (beginning with $\mathfrak{B}$ and before each variable $\mathfrak{B}$ ) with one variable, which are pairwise non-equivalent.

II. There is an infinite number of pairwise non-equivalent formulas of the Heyting calculus with one variable.]

Four years after Gödel's 1932 publication, the paper Jaśkowski (1936) introduced two operations on many-valued systems. Whereas one of these operations can be seen as a product operation leading to a new combined system, the other one (called $\Gamma$ ) adds a single truth-value to a given system and inductively defines implication, negation, disjunction, and conjunction on the extended set of truthvalues. Although Jaśkowski never mentions Gödel's work, it is interesting to note that, starting with the ordinary two-valued system, a repeated application of the $\Gamma$-operator produces the series of Gödel's finite-valued systems.

Another three-valued logic appeared in 1938, when Dmitri A. Bochvar analysed Russell's and Grelling's antinomies in Bochvar (1938). In this paper, 'internal and external forms of assertions' are regarded, both forms leading to different interpretations of the logical connectives. Here, we show only the definitions for the internal forms. For the external view, see Malinowski (1993, chapter 7.2). The tables for negation and conjunction are given as primitives, disjunction and implication being defined as $a \vee b \stackrel{\text { Def }}{=} \sim(\sim a \wedge \sim b)$ and $a \supset b \stackrel{\text { Def }}{=} \sim(a \wedge \sim b)$, respectively.

\begin{tabular}{|c|c|c|c|c|c|c|c|c|c|c|c|}
\hline$\supset$ & 0 & . & & $\sim$ & V & 0 & & 1 & $\wedge$ & 0 & $\begin{array}{ll}\frac{1}{2} & 1\end{array}$ \\
\hline 0 & 1 & . & 0 & 1 & 0 & 0 & $\frac{1}{2}$ & 1 & 0 & & $\begin{array}{ll}\frac{1}{2} & 0\end{array}$ \\
\hline$\frac{1}{2}$ & $\frac{1}{2}$ & $\frac{7}{2}$ & $\frac{1}{2}$ & $\frac{1}{2}$ & $\frac{1}{2}$ & $\frac{1}{2}$ & & $\frac{1}{2}$ & $\frac{1}{2}$ & $\frac{1}{2}$ & $\frac{1}{2} \quad \frac{1}{2}$ \\
\hline 1 & 0 & . & 1 & 0 & 1 & 1 & $\frac{1}{2}$ & 1 & 1 & 0 & $\frac{1}{2} \quad 1$ \\
\hline
\end{tabular}

Finally, when investigating partially defined predicates, Stephen C. Kleene introduced a three-valued logic in Kleene (1938). Here, he gives the following truth-value tables:

\begin{tabular}{|c|c|c|c|c|c|c|c|c|c|c|c|}
\hline$\supset$ & 0 & 1 & & $\sim$ & V & 0 & $\frac{1}{2}$ & 1 & $\wedge$ & 0 & $\frac{1}{2}$ \\
\hline 0 & 11 & 11 & $\overline{0}$ & 1 & 0 & 0 & $\frac{1}{2}$ & 1 & 0 & 0 & 0 \\
\hline$\frac{1}{2}$ & $\frac{1}{2}$ & $\begin{array}{ll}\frac{1}{2} & 1\end{array}$ & $\frac{1}{2}$ & $\frac{1}{2}$ & $\frac{1}{2}$ & $\frac{1}{2}$ & $\frac{1}{2}$ & 1 & $\frac{1}{2}$ & 0 & $\frac{1}{2}$ \\
\hline 1 & 0 & 1 & 1 & 0 & 1 & 1 & 1 & 1 & 1 & 0 & $\frac{1}{2}$ \\
\hline
\end{tabular}

Note that the equations $a \supset b=\sim a \vee b$ and $a \vee b=\sim a \supset b$ hold within these tables. Also, $a \vee b=\max \{a, b\}$ and $a \wedge b=\min \{a, b\}$ hold again. Many years later, in 1952, Kleene called these tables 'strong' as opposed to 'weak' connectives which coincide with those given by Bochvar in 1938. For details, see Kleene (1952, chapter XII).

§3. Gödel's Arbeitheft 1940. By the end of 1940, Gödel had written seven pages of notes and calculations headed 'Lukasiewicz, mehrwertige Logik (System $\mathfrak{S}$ mit unendlich vielen Werten, $\mathfrak{S}_{3}$ mit 3 Werten)' [Lukasiewicz, many-valued 
logic (system $\mathfrak{S}$ with infinitely many values, $\mathfrak{S}_{3}$ with 3 values)]. These notes can be found in his Arbeitsheft 7 [workbook 7], ${ }^{7}$ which is part of a series of notebooks Gödel had started in the mid-1930s, and which consists of altogether 16 books summing up to about twelve hundred shorthand pages.

Gödel himself does not give any hint at what the main purpose for his investigations was. Thus, this section will merely present a summary of the definitions and theorems he considers. The following section will then concentrate on some closely connected philosophical notes which hopefully throws some light upon Gödel's intuitions.

Clearly central to his workbook notes are Lukasiewicz's definitions of negation and implication, ${ }^{8}$ which Gödel repeats as

$$
\begin{gathered}
N e g(x)=1-x \\
x \supset y=\min (1,1-x+y)
\end{gathered}
$$

These definitions are accompanied by the following table and comments:

\begin{tabular}{c|ccc|c}
$x \supset y$ & 0 & $\frac{1}{2}$ & 1 & $x$ \\
\hline 0 & 1 & $\frac{1}{2}$ & 0 & \\
$\frac{1}{2}$ & 1 & 1 & $\frac{1}{2}$ & \\
1 & 1 & 1 & 1 & \\
\hline$y$ & \multicolumn{5}{c}{} \\
viell. $\supset$ falsch $=$ viell. \\
wahr $\supset$ viell. $=$ viell. ${ }^{9}$
\end{tabular}

Gödel then immediately proceeds with two definitions for a disjunction and a conjunction which both clearly differ from what Łukasiewicz himself had defined both in 1920 and in 1930. They also differ from all the other systems given in the proceding section which had been published until the end of 1940, now deviating from the established principle which regards disjunction and conjunction as the maximum and minimum, respectively, of their operands. Gödel's own definitions read as follows:

$$
\begin{gathered}
p \vee^{\prime} q={ }_{D f} \sim p \supset q \\
p .^{\prime} q={ }_{D f} \sim\left(\sim p \vee^{\prime} \sim q\right)
\end{gathered}
$$

And after a few short calculations based on definitions (13) and (14) he adds:

$$
\begin{gathered}
x \vee^{\prime} y=\min (1, x+y) \\
x .^{\prime} y=\max (0, x+y-1)
\end{gathered}
$$

Nowadays, the connectives defined in (7) and (15) ((8) and (16)) are often refered to as weak and strong Lukasiewicz disjunction (conjunction), respectively, see e.g. Gottwald (2001, p. 181). It seems, though, that the distinction between weak and strong connectives originates with Kleene (1952, p. 334). Also, Gottwald

\footnotetext{
${ }^{7}$ Kurt Gödel Papers, Box 5c, Folder 19, item accession 030025.

${ }^{8}$ Throughout this section, we follow Gödel's logical notation.

${ }^{9}$ maybe $\supset$ false $=$ maybe, true $\supset$ maybe $=$ maybe
} 


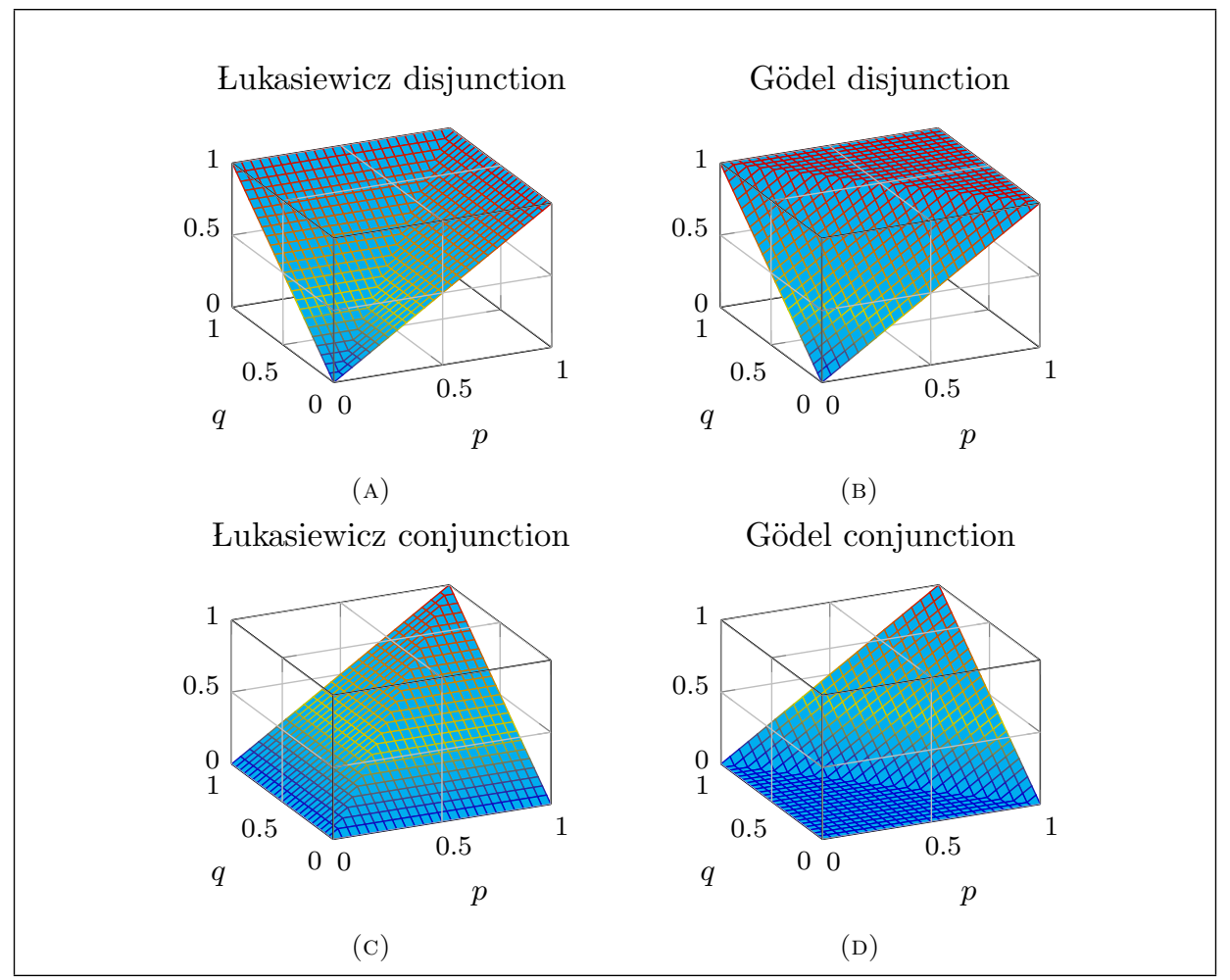

Figure 1. A comparison between disjunction and conjunction as defined by Lukasiewicz in 1930 and by Gödel in his Arbeitsheft in 1940 .

(2001, p. 65) claims that a conjunction as given in (16) 'also (implicitely) appeared already in the initial papers by Łukasiewicz,' but we have not been able to trace any satisfactory hints. In consequence, Gödel's investigations appear to be of independent and genuine character. To facilitate a comparison, Figure 1 illustrates the fundamental properties of the competing definitions for disjunction and conjunction. ${ }^{10}$ Note how in each case the validity of De Morgan's law, based on Łukasiewicz's definition of negation (6), is mirrored by a simple rotation of the corresponding surfaces.

In Figure 2, we list (in the order of their appearance) the theorems given in Gödel's notes, most of which are accompanied by small approving calculations and the comment ' $\varepsilon \mathfrak{S}$.'

In addition (see Figure 3), Gödel also names a few classical theorems which are not theorems of $\mathfrak{S}_{3}$ and therefore also not of $\mathfrak{S}$. These are marked by the comment ' $\sim \varepsilon \mathfrak{S}_{3}$,' in most cases accompanied by an explicit counterexample.

\footnotetext{
${ }^{10} \mathrm{~A}$ detailed comparison between different three-valued implications and conjunctions is given in Ciucci \&S Dubois (2013). In that paper, Gödel's conjunction definition, reduced to three values, is also named after Łukasiewicz.
} 


$$
\begin{gathered}
p .^{\prime} q \leq p \\
p \leq p \vee^{\prime} q \\
p \leq q \rightarrow(p \supset q)=1 \\
p \supset p \vee^{\prime} q \\
p .^{\prime} q=\sim(p \supset \sim q)^{\circ} \\
p \vee^{\prime} \sim p^{\circ} \\
p \supset q=1 \equiv p \leq q \\
p \vee q=\max (p, q)^{\circ} \\
p . q=\min (p, q)^{\circ} \\
(\sim p \vee q) \supset(p \supset q) \\
p . q \leq p \quad p \cdot q \leq q \\
p .^{\prime} q \leq p \cdot q^{\circ} \\
p \supset(q \supset p . q) \\
p .^{\prime} \sim p \supset q^{\circ} \\
p \supset(\sim p \supset r) \\
p \supset\left(q \supset p .^{\prime} q\right) \\
(p \supset q) \supset[(q \supset r) \supset(p \supset r)] \\
p \supset 1=1 \quad 1 \supset p=p \\
q \supset(p \supset q) \\
p \supset(q \supset r) \equiv q \supset(p \supset r) \\
p \cdot p \equiv p^{\circ} \\
(p \supset q) \vee(q \supset p)
\end{gathered}
$$

Figure 2. Formulas verified in Gödel's Arbeitsheft. In those marked $\left({ }^{\circ}\right)$, the operators .' and . $\left(V^{\prime}\right.$ and $\left.\vee\right)$ cannot be interchanged.

$$
\begin{gathered}
(p \supset q) \supset(\sim p \vee q) \\
p \cdot \sim p \supset q \\
p \supset(q \supset r) . \equiv .(p . q) \supset r \\
p \supset(q \supset r) \cdot \supset \cdot(p . q) \supset r \\
(p \supset(p \supset q)) \supset(p \supset q) \\
p \supset p .^{\prime} p \\
(p \supset \sim p) \supset \sim p \\
(\sim p \supset p) \supset p \\
(q \supset r) \supset[(q \supset \sim r) \supset \sim q]
\end{gathered}
$$

Figure 3. Formulas falsified in Gödel's Arbeitsheft. For most of these, Gödel gives counterexamples in $\mathfrak{S}_{3}$. 
Furthermore, Gödel gives the following 'Schlussregeln' (rules of inference) for the System S:

$$
\begin{gathered}
P \varepsilon \mathfrak{S} . Q \varepsilon \mathfrak{S} \rightarrow P . ' Q \varepsilon \mathfrak{S} \\
P \varepsilon \mathfrak{S} . P \supset Q \varepsilon \mathfrak{S} \rightarrow Q \varepsilon \mathfrak{S} \\
\text { 'Deduction Theorem' } \\
P \supset(Q \supset R) \varepsilon \mathfrak{S} . P \supset Q \varepsilon \mathfrak{S} \rightarrow P \supset R \varepsilon \mathfrak{S}
\end{gathered}
$$

Finally, he gives one rule which is commented as ' $\sim \varepsilon \mathfrak{S}_{3}$.'

$$
Q \supset R \varepsilon \mathfrak{S} . Q \supset S \varepsilon \mathfrak{S} . R \supset(S \supset T) \varepsilon \mathfrak{S} \rightarrow Q \supset T \varepsilon \mathfrak{S}
$$

The immediately following page of Gödel's notebook is headed 'Russell Antinomie ohne Negation mit alleiniger Verwendung des positiven Aussagenkalküls' (Russell Antinomy without negation, using only the positive propositional calculus) and here Gödel calls the expression $(p \supset(p \supset q)) \supset(p \supset q)$ the 'entscheidende Formel' (crucial formula) for the appearance of the antinomy in any logical system. In his proof, a second formula, $((p \supset q) \supset p) \supset((p \supset q) \supset q)$, is actually taken as a basis, and it should be interesting to note that both formulas are not valid in either $\mathfrak{S}$ or $\mathfrak{S}_{3} .{ }^{11}$ In his notes on many-valued logic, Gödel adds the comment: 'Wenn $P \supset \sim P$ bewiesen und $\sim P \supset P$ bewiesen, folgt kein Widerspruch in $\mathfrak{S}^{\prime}$ (If $P \supset \sim P$ proved and $\sim P \supset P$ proved, no contradiction follows in $\mathfrak{S})$, thus clearly alluding to the internal logical structure of Russell's antinomy. Note that Łukasiewicz himself had already written in 1920 (Lukasiewicz 1920):

Some laws of two-valued logic are false in three-valued logic, among others the law $\left(a=a^{\prime}\right)=0$, because when $a=2$ the sentence $a=a^{\prime}$ is true. From this fact results the absence of antinomies in three-valued logic. ${ }^{12}$

§4. Epistemological compatibility. Although Lukasiewicz insisted that 'both disjunction and conjunction of two possible propositions are possible propositions (and nothing else)' (cf. Malinowski 1993, p. 19), this attitude leads to difficulties when interpreting the propositions $a \vee \neg a$ and $a \wedge \neg a$, which, despite of an indeterminacy of the proposition $a$, should have a determinate truth-value 1 or 0 , respectively. Whereas these kinds of difficulties, which have been called 'a serious blow upon Łukasiewicz's conception' (Malinowski 1993, p. 21), might well have led Gödel to his new definitions of disjunction and conjunction, this section will mainly concentrate on the interplay between implication and conjunction, which is another possible source for his investigations.

Very often, Gödel's formal work is accompanied by philosophical notes which shed further light upon a possible motivation and a wider context into which the considered details may be embedded. In the case of his Arbeitshefte, the corresponding philosophical notes can, most of the time, be found in his MaxPhil

\footnotetext{
${ }^{11}$ In $\mathfrak{S}_{3}$, both formulas have the one and only common counterexample $p=\frac{1}{2}, q=0$. For details about Gödel's proof and the role of the two 'crucial' formulas, see Lethen (2020a).

${ }^{12} a^{\prime}$ is Eukasiewicz's notation for the negation of $a .2$ is his third (possible) truth-value.
} 
books, a series of 16 notebooks written between 1934 and the later 1950s. ${ }^{13}$ Here, when investigating Lukasiewicz's three-valued logic at the end of 1940, Gödel noted (MaxPhil III, p. 44): ${ }^{14}$

In der mehrwertigen Logik ist der Wahrheitswert von $q<$ als die Wahrheitswerte von $p, p \supset q$, d.h. (wenn durch 'Klarheit' interpretiert), nach endlich vielen Schlüssen hört jeder Grad von Klarheit auf, d.h., man sieht nichts mehr. Das deutet darauf hin, dass, um weitergende Folgerungen zu erzielen, man versuchen muss, die einfachen Dinge vollkommen klar zu sehen. Es gibt vielleicht auch eine natürliche Reihenfolge der Wissenschaften, nämlich: zuerst die Fundamente aller Wissenschaften, dann das Kompliziertere aller Wissenschaften, etc. (harmonische Ausbildung).

[In many-valued logic, the truth-value of $q$ is smaller than the truthvalues of $p, p \supset q$, i.e. (if interpreted by 'clarity'), after a finite number of conclusions, any degree of clarity ceases to exist, i.e. one sees nothing. This indicates that in order to reach further conclusions, one must try to see the simple things completely clearly. There is perhaps also a natural order of the sciences, namely: first the foundations of all sciences, then the more complicated of all sciences, etc. (harmonious education).]

It has to be noted here that the first part of this quote certainly cannot be taken in the literal sense because, of course, the truth-value of a proposition $q$ may well be smaller than the values of a second independent proposition $p$ or than the implication $p \supset q$. At a closer look at Gödel's writing one recognises, though, that the passage in question has apparently (wrongly) been overwritten at a later time and originally probably read 'the truth-value of $q$ is smaller than the truth-values of $p . p \supset q$,' in which the conjunction of $p$ and $p \supset q$ does indeed make perfect sense in the given context.

Although Gödel does not explicitly require here that the truth-value of a proposition $q$ should always exceed the value of the conjunction $p \cdot p \supset q$, and indeed readily seems to accept the opposite attitude, the inequation

$$
p .(p \supset q) \leq q
$$

can be considered a fundamental epistemological law for the interplay between implication and conjuction, taking for granted that the deductive argument of modus ponens should determine a lower bound for the truth or evidence of the detached proposition. And whereas the counterexample $p=\frac{1}{2}$ and $q=0$ shows that Łukasiewicz's many-valued logic does indeed not conform to this epistemological compatibility of implication and conjunction, two short calculations considering the cases $p \leq q$ and $p>q$ reveal that Gödel's 1940 definition of conjunction is compatible with Lukasiewicz implication. Finally, as far as the interplay between implication and conjunction is concerned, it should also be noted that the formula $(p \supset q) \supset\left(\left(p .^{\prime} r\right) \supset\left(q .^{\prime} r\right)\right)$ expressing a kind of monotonicity is valid in both $\mathfrak{S}_{3}$ and $\mathfrak{S}$.

\footnotetext{
${ }^{13}$ For a detailed description of these notebooks, see Engelen (2019).

${ }^{14}$ Kurt Gödel Papers, Box 6b, Folder 66, item accession 030089.
} 
It is difficult to decide whether the question of an epistemological compatibility initiated Gödel's considerations of his new definitions of disjunction and conjunction. Interestingly, the formula $p .(p \supset q) \supset q$ had already been an axiom in Heyting's axiomatization of intuitionistic logic in 1930 (Heyting 1930). So in 1932, when Gödel proved that intuitionistc propositional logic cannot be regarded as a (finite) system of many-valued logic, he most certainly did know that Lukasiewicz's implication and conjunction were not compatible in the epistemological sense. Following Heyting, he then used a different kind of implication, abiding with Lukasiewicz's conjunction. His considerations in Arbeitsheft 7 now follow the opposite direction. ${ }^{15}$

§5. First-order Logic. Probably one of the earliest signs of an application of a first-order many-valued system can be found in Carl Hempel and Paul Oppenheim's book 'Der Typusbegriff im Lichte der neuen Logik' (Hempel 83 Oppenheim 1936), which was published in 1936 and was mainly written for psychologists working in the field of typology. ${ }^{16}$ Right at the beginning of the book, considering their main approach, the authors write (p. 2):

Jedes solche Merkmal wird nun einem Objekt entweder zugeschrieben oder abgesprochen, und wenn man jeweils alle Objekte mit einem bestimmten Merkmal in eine Gruppe zusammenfasst, so entstehen Einteilungen in scharf gegeneinander abgegrenzte Klassen; jede mögliche Verfeinerung der Beschreibung empirischer Objekte beruht dieser Auffassung zufolge auf der Einführung neuer Merkmalsbegriffe, die jeweils eine Unterteilung der bestehenden Einteilung nach sich zieht. - Im Gegensatz hierzu, so meint die geschilderte Auffassung, kommt den empirischen Objekten eine bestimmte Eigenschaft im allgemeinen keineswegs entweder zu oder nicht zu; es bestehen vielmehr mannigfaltige Zwischenstufen zwischen diesen beiden 'extremen' Möglichkeiten: Eine Eigenschaft kann einem Gegenstand in der Regel in mehr oder minder hohem Grade zukommen;

[Each such property is now either attributed to an object or rejected, and if all objects with a particular property are grouped together, classifications into distinct classes arise; any possible refinement of the description of empirical objects is, according to this view, based on the introduction of new properties, each of which entails a subdivision of the existing classification. - In contrast to this, the view described here is that empirical objects generally do not have a certain property either or not at all; rather, there are manifold intermediate stages between these two 'extreme' possibilities: Generally, a property can be assigned to an object to a greater or lesser degree;]

\footnotetext{
${ }^{15}$ Note that, using Gödel's 1940 conjunction, the formula $a \supset\left(a .^{\prime} a\right)$, which is Heyting's first axiom, is not valid. Therefore, this kind of conjuction could not have been used alternatively in his 1932 proof.

${ }^{16}$ The book was reviewed in Grelling (1936), where it was called 'die erste Anwendung der logistischen Methoden auf wissenschaftstheoretische Probleme außerhalb des Bezirks der exakten Wissenschaften' (the first application of logistic methods to problems of scientific theory outside the field of the exact sciences).
} 
Without any doubt, it can be assumed that Gödel was quite familiar with this book. It was mentioned during a meeting in December 1937 at Edgar Zilsel's home as well as in a conversation in early 1938 with Max Söderman, ${ }^{17}$ who, according to Gödel's protocols, calls it a 'reasonable application of logistics. ${ }^{18}$ Only a few years later, in 1943, Gödel wrote down the following affirmative philosophical notes about these 'real' empirical objects and their properties, which can be found in his notebook MaxPhil $X^{19}$ (p. 20):

Bemerkung (Philosophie): Die Wahrheit (oder die Wahrheiten) sind ein Teil der Realität, indem die Realität aus zwei Teilen besteht, nämlich den Dingen und den Tatsachen. (Das sind die 'Verbindungen' zwischen den Dingen.) $a \varepsilon b$ bedeutet: $a$ und $b$ sind 'im Sein' verbunden. Es gibt Grade dieser Verbindung. (Man kann fast alle Eigenschaften in Graden haben.) Eine Tatsache enthält also ihre Constituenten nicht als Teile, sondern ist das Band, das diese Constituenten zusammenhält.

[Remark (philosophy): Truth (or truths) are a part of reality, in that reality consists of two parts, namely objects and facts. (These are the 'connections' between the objects.) $a \varepsilon b$ means: $a$ and $b$ are connected 'in existence.' There are degrees of this connection. (One can have almost all properties in degrees.) So a fact does not contain its constituents as parts, but is the string that holds these constituents together.]

And later in the same book he continues (p. 65):

Bemerkung (Philosophie): Von allen exakten Wissenschaften hat die Mathematik am wenigsten mit Größe zu tun, da die Eigenschaften, die sie behandelt, nicht graduell sind, während in anderen (Physik, Jurisprudenz, Psychologie, Ökonomie) die Aussagen überhaupt erst einen Sinn bekommen, wenn der Grad der Eigenschaften oder Relationen determiniert wird. Die Größe einer Eigenschaft ist vielleicht 'der Grad der Realisierung'. (Daher im Raum der Platonischen Ideen keine Größe.) Die Wahrheitswerte daher Spezialfall, und zwar unendlich groß wegen $p \cdot p=p$. Dagegen bedeutet ' $A$ ist hell und $A$ ist hell': ' $A$ ist sehr hell' (vgl. 'HERR, HERR').

[Remark (philosophy): Of all the exact sciences, mathematics has the least to do with quality [Größe], since the properties it deals with are not gradual, whereas in others (physics, jurisprudence, psychology, economics) the statements only make sense when the degree of the properties or relations is determined. The quality of a property is perhaps 'the degree of realisation.' (Therefore there is no quality in the space of Platonic ideas.) The truth values are therefore a special case, and infinitely large because $p \cdot p=p$. On the other hand, ' $A$

\footnotetext{
${ }^{17}$ Max Söderman (1914-1947), a student of philosopher Eino Kaila from Helsinki, Finland, stayed in Vienna in 1937/1938 and appears to have been in close contact to Gödel.

${ }^{18}$ For details on these occasions, see Lethen (2020b).

${ }^{19}$ Kurt Gödel Papers, Box 6b, Folder 70, item accession 030096.
} 


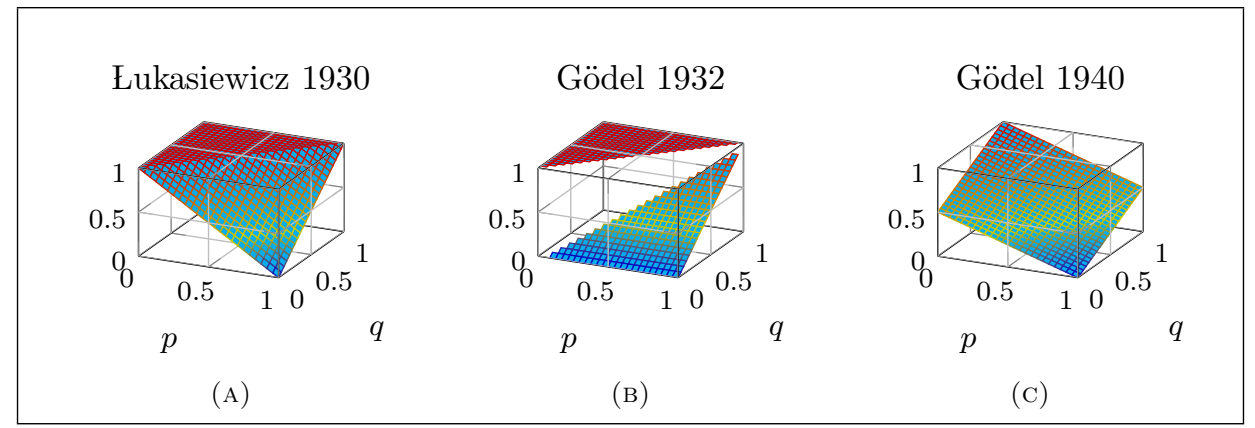

Figure 4. A comparison between three different kinds of implication $p \supset q$ : (A) Eukasiewicz's implication 1930 [definition (5)], (B) Gödel's implication 1932 [definition (9)], (C) the implication based on Gödel's philosophical notes 1940 [definition $(20)]$.

is bright and $A$ is bright' means: ' $A$ is very bright' (compare 'Lord, Lord').]

The very last sentence is certainly hard to interpret because the subexpression $\mathcal{H}(A)$ representing the proposition ' $A$ ist hell' ( $A$ is bright) obviously cannot have different degrees or values within the one expression $\mathcal{H}(A) . \mathcal{H}(A) \supset \mathcal{H}(A)$. Instead, a possible interpretation of Gödel's statement could consider the expression $\mathcal{H}(A) \cdot \mathcal{H}(A) \supset \mathcal{H}(A)$ a stronger implication than $\mathcal{H}(A) \supset \mathcal{H}(A)$. In order to support this approach, two conditions have to be met:

1. The value of $\mathcal{H}(A) \supset \mathcal{H}(A)$ is smaller than 1 .

2. The expressions $\mathcal{H}(A)$ and $\mathcal{H}(A) . \mathcal{H}(A)$ have different truth-values.

Whereas the second condition is perfectly met by the conjunction defined by Gödel in his Arbeitsheft in 1940 (see definition (16) and equation (18)), the following new definition of an implication now assigns the truth-value 0.5 to the expression $\mathcal{H}(A) \supset \mathcal{H}(A)$. Note that the truth-values 0 and 1 are assigned only to the implications $1 \supset 0$ and $0 \supset 1$, respectively.

$$
p \supset q \stackrel{\text { Def }}{=} 0.5 \cdot(1+q-p)
$$

As an example, we can now consider a situation in which $\mathcal{H}(A)=0.9$. In this case, we get $\mathcal{H}(A) \cdot \mathcal{H}(A)=0.8$. The corresponding implications then yield the values $\mathcal{H}(A) \supset \mathcal{H}(A)=0.5$ and $\mathcal{H}(A) \cdot \mathcal{H}(A) \supset \mathcal{H}(A)=0.55$, respectively. Figure 4 allows for a comparison between Łukasiewicz's implication, Gödel's published 1932 version, and the new definition (20). Note the continuous differentiability of the new kind of implication.

We conclude this section with the comment that Gödel was a great expert on the German and the Latin Bible and often carried his philosophical thoughts back and forth into a biblical setting. Here, his comment "vgl. "HERR, HERR"' must be taken as such an example. The phrase, which is Luther's usual translation of the Latin 'Domine, Domine' (or 'Domine Deus' in some cases), ${ }^{20}$ appears in

${ }^{20}$ The English translation in King James' Bible usually is 'Lord, Lord' or 'Lord GOD.' 
many places both in the Old and the New Testament of the Luther Bible ${ }^{21}$ and apparently serves - in Gödel's eyes - as a strengthening of the form of address in the above sense of a strengthened implication. Other examples of Gödel's inclusion of the Bible in his philosophical thoughts can be found in Lethen (2020a) and Lethen (2020c).

§6. A metaphysical application. This Section briefly touches upon an early application of a higher-order multi-valued logic in a metaphysical and theological context. For Gödel, one of the basic concepts of metaphysics and philosophy in general was positivity. ${ }^{22}$ It served as a basis for his ontological proof for the necessary existence of God, and formal axiomatizations can be found in several places in his Nachlass.

In one of his approaches to the notion of positivity, Gödel takes goodness as an even more basic concept, a second-order property which can be assigned to first-order properties in different 'intensities,' i.e. in different degrees. Again in the notebook MaxPhil X (p. 70), he writes:

Es gibt aber verschiedene Arten des Guten (nicht nur verschiedene Intensitäten), und es gibt Gutes, das eine Vielheit in sich hat. (Man ist gleichzeitig auf verschiedene Weisen glücklich.)

[But there are different kinds of good (not just different intensities) and there is good that has a multitude inside. (One is happy in different ways at the same time.)]

Whereas the 'different kinds of good' and the 'multitude inside' refer to a typed hierarchy amongst positive properties ${ }^{23}$ the 'different intensities' apparently allude to degrees of properties in the sense of Hempel and Oppenheim (see Section $5)$. Note that the idea of different degrees of good in connection with God's properties already appears in Anselm of Canterbury's Proslogion, ${ }^{24}$ which was certainly well known to Gödel. This view is supported by later writings in the notebook MaxPhil XIV, ${ }^{25}$ where Gödel remarks (p. 103):

Philosophie: Der ontologische Beweis muss ${ }^{26}$ auf den Begriff des Wertes ( $p$ besser als $\sim p$ ) gegründet werden und auf die Axiome:

1. Logisch Äquivalente haben den gleichen Wert. (Daher immer notwendig $\varphi$ oder $\sim \varphi$ positiv.)

2. Wenn $p, q$ negative Werte haben, so auch $p \vee q$.

3. $N p, M p$ negativ, wenn $p$ negativ.

4. Das Sein ist positiv.

[Philosophy: The ontological proof must be based on the concept of value ( $p$ better than $\sim p$ ) and on the axioms:

\footnotetext{
${ }^{21}$ See for example Genesis 15:2 and Matthiew 7:21.

${ }^{22}$ It appears on a list of basic concepts on a loose sheet in his Nachlass. For details, see Lethen (2020d).

${ }^{23}$ Details are given in Lethen (2020a).

${ }^{24}$ See for example the end of chapter XI.

${ }^{25}$ Kurt Gödel Papers, Box 6b, Folder 72, item accession 030099. This passage has also been published in Feferman \& al. (1995, p. 432).

${ }^{26} \mathrm{~A}$ question mark is written above the word 'muss'.
} 
1. Logical equivalents have the same value. (Therefore always necessarily $\varphi$ or $\sim \varphi$ positive.)

2. If $p, q$ have negative values, so does $p \vee q$.

3. $N p, M p$ negative if $p$ negative.

4. Being is positive.]

Here, $p, \sim p, p \vee q$ etc. are to be taken as properties rather than propositions throughout. Based on the idea of different degrees of the second-order property Good, positivity of a property $\varphi$ may now, in Gödel's sense, be defined in a multi-valued setting as follows:

$$
\operatorname{Pos}(\varphi) \equiv(\operatorname{Good}(\sim \varphi)<\operatorname{Good}(\varphi))
$$

In consequence, as intended by Gödel, positivity itself does not appear in different degrees but only as true or false.

§7. Conclusion. Gödel himself often remarked that his work in logic and the foundations of mathematics was constantly closely interwoven with philosophical considerations. As we have now been able to show, his work in many-valued logic was no exception to this rule. In consequence, as a major portion of Gödel's writings is still slumbering unpublished in his huge Nachlass, future investigations, if striving for a complete and comprehensive understanding of his scientific work, will not be able to avoid a parallel examination of both the formal and the philosophical parts of his notebooks and papers.

Acknowledgements. I would like to thank Jan von Plato, Helsinki, for his encouraging support. Again, this paper would not have been possible without his vast knowledge of Gödel's Nachlass. I also thank Maria Hämeen-Anttila for her help with Gödel's papers preparing the Hahn seminar, as well as Marcia Tucker (IAS, Princeton) for her assistance.

The research for this article is a part of the GöDELIANA project led by Jan von Plato. This project has received funding from the European Research Council (ERC) under the European Union's Horizon 2020 research and innovation programme (Grant Agreement No. 787758) and from the Academy of Finland (Decision No. 318066).

\section{REFERENCES.}

Bernays, P. (1918) Beiträge zur axiomatischen Behandlung des Logik-Kalküls. Habilitationsschrift, Universität Göttingen. Bernays Nachlass, WHS, Bibliothek, ETH Zürich, Hs. 973.192. Printed in: W. Ewald \& W. Sieg (Eds.) (2013), David Hilbert's Lectures on the Foundations of Arithmetic and Logic 19171933. Berlin: Springer, pp. 231-269.

Bernays, P. (1926) Axiomatische Untersuchung des Aussagen-Kalküls der 'Principia Mathematica'. Mathematische Zeitschrift, 25, 305-320.

Bochvar, D. A. (1938) Ob odnom tréchznačnom isčislénii i égo priménénii k analizu paradoksov klassičéskogo rasširennogo funkcjonal'nogo isčislénija. 
Matématičéskij Sbornik, 4(46), 287-308. English translation: Bochvar \& Bergmann (1981).

Bochvar D. A. \& Bergmann, M. (1981) On a three-valued logical calculus and its application to the analysis of the paradoxes of the classical extended functional calculus. History and Philosophy of Logic, 2(1-2), 87-112.

Ciucci, D., \& Dubois, D. (2013) A map of dependencies among three-valued logics. Information Sciences, 250, 162-177.

Engelen, E.-M. (2019) Kurt Gödel - Philosophische Notizbücher, Volume 1: Philosophie I Maximen 0. Berlin: De Gruyter.

Feferman, S., et al. (eds.) (1995) Kurt Gödel, Collected Works. Vol. III. Unpublished Essays and Lectures. New York: Oxford University Press.

Gödel, Kurt. (1932) Zum intuitionistischen Aussagenkalkül. Anzeiger der Akademie der Wissenschaften in Wien, 69, 65-66.

Gödel, Kurt. (2021) Results on Foundations. Edited by Maria Hämeen-Anttila and Jan von Plato. In preparation.

Gottwald, S. (2001) A Treatise on Many-Valued Logics. Studies in Logic and Computation, vol. 9. Baldock: Research Studies Press.

Grelling, K. (1936) Der Typusbegriff im Lichte der neuen Logik, von C. G. Hempel \& P. Oppenheim (Besprechung). Erkenntnis, 6, 266-268.

Hempel, C. G. \& Oppenheim, P. (1936) Der Typusbegriff im Lichte der neuen Logik. Leiden: Sijthoff.

Heyting, A. (1930) Die formalen Regeln der intuitionistischen Logik. Sitzungsberichte Preußische Akademie der Wissenschaften Berlin, physikalischmathematische Klasse II, 42-56.

Heyting, A. (1934) Mathematische Grundlagenforschung: Intuitionismus, Beweistheorie. Berlin: Springer.

Jaśkowski, S. (1936) Recherches sur le système de la logique intuitioniste. Actes du Congrès International de Philosophie Scientifique, 6, 58-61. English translation: Jaśkowski (1975).

Jaśkowski, S. (1975) Investigations into the System of Intuitionist Logic. Studia Logica: An International Journal for Symbolic Logic, 34(2), 117-120.

Kleene, S. C. (1938) On a notation for ordinal numbers. The Journal of Symbolic Logic, 3, 150-155.

Kleene, S. C. (1952) Introduction to metamathematics. Amsterdam: NorthHolland.

Lethen, T. (2020a) Kurt Gödel on logical, theological, and physical antinomies. Submitted for publication.

Lethen, T. (2020b) Gespräche, Vorträge, Séancen: Kurt Gödels Wiener Protokolle 1937/38 - Transkriptionen und Kommentare. To appear.

Lethen, T. (2020c) Mistakes in the Bible - Kurt Gödel's biblical Studies. Submitted for publication.

Lethen, T. (2020d) Kurt Gödel's dogmatic logic. In: E. Ramharter (Ed.), Vienna Circle and Religion. To appear.

Łukasiewicz, J. (1920) O logice trójwartościowej, Ruch Filozoficny, 5, 170-171. English translation in Mc Call (1967).

Łukasiewicz, J. (1930) Philosophische Bemerkungen zu mehrwertigen Systemen des Aussagenkalküls. Comptes rendus des séances de la Société des Sciences 
et des Lettres de Varsovie, Cl. iii, 23, 51-77. English translation in McCall (1967).

Łukasiewicz, J. \& Tarski A. (1930) Untersuchungen über den Aussagenkalkül. Comptes rendus des séances de la Société des Sciences et des Lettres de Varsovie, Cl. iii, 23, 30-50.

Malinowski, G. (1993) Many-Valued Logics. Oxford: Oxford University Press.

McCall, S. (1967) Polish Logic, 1920-1939. Oxford: Oxford University Press.

von Plato, J. (2017) The Great Formal Machinery works: Theories of Deduction and Computation at the Origins of the Digital Age. Princeton: Princeton University Press.

von Plato, J. (2020) Can Mathematics be Proved consistent? Gödel's Shorthand Notes 83 Lectures on Incompleteness. Berlin: Springer.

von Plato, J. (2021) Logicism and antinomies, logical calculus and metamathematics: Chapters from Gödel's unfinished book on foundational research in mathematics. In preparation.

Post, E. L. (1921) Introduction to a general theory of elementary propositions. American Journal of Mathematics, 43(3), 163-185.

Zach, R. (1999) Completeness before Post: Bernays, Hilbert, and the Development of Propositional Logic. The Bulletin of Symbolic Logic, 5(3), 331-366. 